\title{
Risk Factors for Chest Pain and Fever in Patients Undergoing Pleurodesis with OK-432
}

\author{
Yoshihito Morimoto ${ }^{1}$, Hidefumi Takei ${ }^{2}$, Keisei Tachibana ${ }^{2}$, Yoko Nakazato ${ }^{2}$, Ryota Tanaka ${ }^{2}$, \\ Yasushi Nagashima ${ }^{2}$, Kazuhiro Watanabe ${ }^{1}$, Reisuke Seki ${ }^{3}$, \\ Takao Shinohara ${ }^{3}$ and Haruhiko Kondo ${ }^{2}$
}

\begin{abstract}
:
Objective In Japan, pleurodesis is often performed using OK-432. However, OK-432 may cause severe chest pain and fever. The risk factors for these complications are unclear. The aim of this study was to identify the risk factors for chest pain and fever caused by pleurodesis with OK-432.

Methods The clinical data of 94 patients who underwent pleurodesis with OK-432 were retrospectively analyzed. Patients who developed chest pain (indicated by a record of rescue pain medication) and/or fever (a recorded temperature of $>38^{\circ} \mathrm{C}$ ) were identified. A logistic regression analysis was performed to determine the risk factors for these complications.

Results Rescue medication for chest pain was required by $43.6 \%$ of the patients and $40.4 \%$ developed pyrexia after pleurodesis with OK-432. The univariate analysis showed that the likelihood of requiring rescue medication for chest pain was significantly increased in patients of $<70$ years of age $(\mathrm{p}=0.028)$ and in those who were not premedicated with a nonsteroidal anti-inflammatory drug (NSAID; $\mathrm{p}=0.003$ ). Age $<70$ years (adjusted odds ratio $2.97,95 \%$ confidence interval 1.10-8.00, $\mathrm{p}=0.031$ ) and a lack of premedication with an NSAID (adjusted odds ratio 4.21, 95\% confidence interval 1.47-12.04, $\mathrm{p}=0.007$ ) remained significant factors in a multivariate analysis. The absence of NSAID premedication was the only statistically significant risk factor for fever in the univariate analysis $(\mathrm{p}=0.034)$. The multivariate analysis revealed no significant risk factors for fever.

Conclusion The results of the present study suggest that premedication with an NSAID might be useful for preventing the chest pain caused by pleurodesis with OK-432. Furthermore, caution is advised when managing chest pain in adults of $<70$ years of age. Prospective studies should be performed to further investigate this issue.
\end{abstract}

Key words: OK-432, pleurodesis, chest pain, fever, risk factors

(Intern Med 57: 1697-1702, 2018)

(DOI: 10.2169/internalmedicine.9637-17)

\section{Introduction}

Pleurodesis is commonly performed in the treatment of patients with malignant pleural effusion, complications after lung surgery, and pneumothorax. The procedure entails the introduction of a sclerosing agent into the pleural space to cause inflammation and the obliteration of the space be- tween the visceral and parietal pleura. OK-432 (a purified preparation derived from Streptococcus pyogenes) is commonly used as a sclerosing agent in Japan. Several studies have shown that OK-432 is useful for pleurodesis (1-3). In Western countries, talc has been the gold standard sclerosing agent for pleurodesis for many years. Talc was approved for pleurodesis in Japan in December 2013, but only for patients with malignant pleural effusion. Thus, OK-432 is a

${ }^{1}$ Education and Research Center for Clinical Pharmacy, Showa Pharmaceutical University, Japan, ${ }^{2}$ Department of General Thoracic Surgery, Kyorin University Hospital, Japan and ${ }^{3}$ Department of Pharmacy, Kyorin University Hospital, Japan

Received: June 8, 2017; Accepted: November 1, 2017; Advance Publication by J-STAGE: February 9, 2018

Correspondence to Dr. Yoshihito Morimoto, y-morimoto@ac.shoyaku.ac.jp 
well-established agent that has been conventionally used for patients with malignant pleural effusion, postoperative complications, and pneumothorax. However, pleurodesis using OK-432 is associated with complications, particularly chest pain and fever $(1,4)$, the reasons for which have not been clarified. The aim of this study was to identify the risk factors for complications in patients undergoing pleurodesis with OK-432.

\section{Materials and Methods}

\section{Patients}

We retrospectively reviewed the medical records in the Department of General Thoracic Surgery, Kyorin University Hospital, and identified 97 potential study participants who had undergone pleurodesis with OK-432 between February 2013 and July 2016. Three patients were excluded (the volume of OK-432 was unclear in two patients and the body height was not measured in 1 patient); thus, the data of 94 patients were available for the analysis. The study was conducted in accordance with the Declaration of Helsinki and the protocol was approved by the Ethics Committee of Kyorin University Hospital (approval number: 776).

\section{Procedure}

In all cases, OK-432 (Picibanil, Chugai Pharmaceutical, Tokyo, Japan) was injected into the pleural space via a 1624 Fr chest tube connected to a water-sealed drainage system. OK-432 was administered at a dose of $5 \mathrm{KE}$ or $10 \mathrm{KE}$ (Klinische Einbeit; $1 \mathrm{KE}$ contains $0.1 \mathrm{mg}$ of dried cocci). Two hundred milligrams of minocycline and lidocaine $1 \%$ could also be administered at the discretion of the attending physician. These drugs were suspended in $20-100 \mathrm{~mL}$ of saline or autologous blood. Lidocaine $(1 \%)$ was administered at the same time or just prior to the administration of $\mathrm{OK}$ 432. The physician also determined the position of the patient in bed. The analgesic agents used before pleurodesis varied from patient to patient.

\section{Evaluation}

Chest pain was defined as the need for rescue pain medication and fever was defined as a body temperature of $>38^{\circ} \mathrm{C}$ after pleurodesis. Fever was evaluated in accordance with the National Cancer Institute Common Terminology Criteria version 4.0.

\section{The risk factors for chest pain and fever}

The following demographic and clinical variables were investigated to determine their relationship with chest pain and fever after pleurodesis with OK-432. The variables were divided into two groups based on the approximate median values: age ( $<70$ or $\geq 70$ years), sex (male or female), body height $(\geq 160$ or $<160 \mathrm{~cm})$, body weight $(\geq 55$ or $<55 \mathrm{~kg}$ ), body surface area $\left(\geq 1.6\right.$ or $\left.<1.6 \mathrm{~m}^{2}\right)$, disease (malignant pleural effusion or not), albumin $(\geq 3.2$ or $<3.2 \mathrm{~g} / \mathrm{dL})$, C- reactive protein $(\geq 3.0$ or $<3.0 \mathrm{mg} / \mathrm{dL}), 24$-h drainage volume on the day before pleurodesis $(\geq 150$ or $<150 \mathrm{~mL})$, dose of OK-432 (10 or $5 \mathrm{KE}$ ), administration of minocycline (yes/ no), administration of autologous blood (yes/no), volume of solution (100 or $\leq 50 \mathrm{~mL}$ ), administration of lidocaine $(1 \%$; yes/no), and premedication with an NSAID, acetaminophen, and/or opioid (yes/no).

\section{Statistical analysis}

Potential risk factors for chest pain and fever caused by pleurodesis with OK-432 were tested by a logistic regression analysis. Factors with an odds ratio $<0.5$ or $>2.0$ in the univariate analysis were included in a multivariate analysis. All of the statistical analyses were performed using the StatView software program (version 5 for Windows, SAS Institute, Cary, USA). $\mathrm{p}$ values of $<0.05$ were considered to indicate statistical significance.

\section{Results}

\section{Patients}

The clinical and demographic characteristics of the 94 patients (male, $n=63$; female, $n=31$ ) who underwent pleurodesis with OK-432 are shown in Table 1. Forty-five of these patients had malignant pleural effusion, 27 had postoperative complications, and 22 had pneumothorax. All 27 postoperative patients had undergone pulmonary tumor resection by video-assisted thoracic surgery. Eighty-four patients (89.4\%) received OK-432 at a dose of $10 \mathrm{KE}$, and $10(10.6 \%)$ received OK-432 at a dose of $5 \mathrm{KE}$. Eleven patients (11.7\%) also received minocycline $(200 \mathrm{mg})$. Forty-eight patients $(51.1 \%)$ received lidocaine $(1 \%)$, the volume of which was $10 \mathrm{~mL}$ in 41 patients, $20 \mathrm{~mL}$ in 5 patients, and unknown in 2 patients. For pain relief, 66 patients $(70.2 \%)$ were premedicated with an NSAID, 22 with acetaminophen (23.4\%) and 29 with an opioid (30.9\%). The NSAIDs included loxoprofen $(60 \mathrm{mg}$, orally, thrice daily; $\mathrm{n}=61,92.4 \%$ ) or celecoxib (200 mg or $400 \mathrm{mg}$, orally, once daily; $\mathrm{n}=5,7.6 \%$ ). Various acetaminophen and opioid regimens were used. Acetaminophen was administered orally at a dose of 325$1,600 \mathrm{mg}$ per day. The daily acetaminophen doses were $1,600 \mathrm{mg}$ for 2 patients; $1,300 \mathrm{mg}$ for 13 patients; 1,200, 975, and $650 \mathrm{mg}$ for 1 patient each; $325 \mathrm{mg}$ for 2 patients; and unknown for 2 patients. The opioids prescribed included tramadol, oxycodone, morphine, and fentanyl. The most commonly used opioid was tramadol (150 mg, daily), which was administered to 19 patients.

\section{The complications of pleurodesis}

The complications of pleurodesis with OK-432 are shown in Table 2. Forty-one patients $(43.6 \%)$ required rescue medication for chest pain, which was usually an NSAID (in $58.5 \%$ of cases), and which was most often diclofenac (50 $\mathrm{mg}$, by suppository). Thirty-eight patients (40.4\%) developed fever, which was graded as $<3$ in all cases. 
Table 1. Patient Clinical and Demographic Characteristics $(n=94)$.

\begin{tabular}{|c|c|}
\hline & Patients (n) \\
\hline Median age, years (range) & $68.5(23-91)$ \\
\hline Sex, Male/Female & $63 / 31$ \\
\hline Median body height, $\mathrm{cm}$ (range) & $161.2(143.3-175.8)$ \\
\hline Median body weight, kg (range) & $54(32.3-89.9)$ \\
\hline Median body surface area $\mathrm{m}^{2}$ (range) & $1.56(1.172-1.984)$ \\
\hline \multicolumn{2}{|l|}{ Disease } \\
\hline Malignant pleural effusion & 45 \\
\hline Complication of lung surgery & 27 \\
\hline Pneumothorax & 22 \\
\hline Median albumin, g/dL (range) & $3.2(1.5-4.7)$ \\
\hline Median C-reactive protein, mg/dL (range) & $3.1(0.1-21.6)$ \\
\hline $\begin{array}{l}\text { Median 24-h drainage volume on the day } \\
\text { before pleurodesis, } \mathrm{mL} \text { (range) }\end{array}$ & $155(0-2,300)$ \\
\hline \multicolumn{2}{|l|}{ Dose of OK-432 } \\
\hline $10 \mathrm{KE} / 5 \mathrm{KE}$ & $84 / 10$ \\
\hline \multicolumn{2}{|l|}{ Administration of minocycline } \\
\hline Yes/No & $11 / 83$ \\
\hline \multicolumn{2}{|l|}{ Administration of lidocaine $1 \%$} \\
\hline Yes/No & $48 / 46$ \\
\hline \multicolumn{2}{|l|}{ Administration of autologous blood } \\
\hline Yes/No & $13 / 81$ \\
\hline \multicolumn{2}{|l|}{ Volume of solution } \\
\hline$\leq 50 \mathrm{~mL} / 100 \mathrm{~mL}$ & $43 / 51$ \\
\hline \multicolumn{2}{|l|}{ Analgesic premedication } \\
\hline \multicolumn{2}{|l|}{ NSAID } \\
\hline Yes/No & $66 / 28$ \\
\hline \multicolumn{2}{|l|}{ Acetaminophen } \\
\hline Yes/No & $22 / 72$ \\
\hline \multicolumn{2}{|l|}{ Opioid } \\
\hline Yes/No & $29 / 65$ \\
\hline
\end{tabular}

KE: Klinische Einbeit, NSAID: nonsteroidal anti-inflammatory drug

\section{The risk factors for needing rescue medication to treat OK-432-related chest pain and fever}

Among the clinical factors that were entered in the univariate analysis, age $<70$ years and no premedication with an NSAID were statistically significant predictors of the need for rescue medication to manage pleurodesis-related chest pain ( $\mathrm{p}=0.028$ and $\mathrm{p}=0.003$, respectively; Table 3 ). No use of lidocaine $(1 \%)$ and no premedication with acetaminophen or an opioid were not significant risk factors.

In the multivariate analysis, age $<70$ years, and no premedication with an NSAID were identified as significant independent predictors of the need for rescue medication to manage pleurodesis-related chest pain (adjusted odds ratio $2.97,95 \%$ confidence interval $1.10-8.00, \mathrm{p}=0.031$, and adjusted odds ratio $4.21,95 \%$ confidence interval 1.47-12.04, $\mathrm{p}=0.007$, respectively; Table 4). A lack of premedication with an NSAID was the only statistically significant predictor of fever in the univariate analysis $(\mathrm{p}=0.034)$; age $<70$ years and a volume of OK-432 exceeding $100 \mathrm{~mL}$ tended to be associated with fever, but not to a statistically significant extent (Table 5). However, the multivariate analysis revealed

\section{Table 2. Complications of Pleurodesis.}

\begin{tabular}{lc}
\hline Rescue medication for chest pain, $\mathrm{n}(\%)$ & 41 (43.6) \\
Rescue medicine & 24 \\
NSAID & 6 \\
Acetaminophen & 5 \\
Opioid and acetaminophen & 4 \\
Opioid & 2 \\
Pentazocine & $38(40.4)$ \\
Fever, $\mathrm{n}(\%)$ & 29 \\
Grade 1 & 9 \\
Grade 2 & 0 \\
Grade 3 & \\
\hline NSAID: nonsteroidal anti-inflammatory drug &
\end{tabular}

no significant risk factors for fever (Table 6). Although it was not statistically significant, the use of NSAIDs tended to be associated with fever caused by pleurodesis with OK432 (adjusted odds ratio $2.43,95 \%$ confidence interval 0.95 6.22, $\mathrm{p}=0.065$ ).

\section{Discussion}

To date, there have been no reports on the risk factors for complications of pleurodesis using OK-432. In the present study, we made some important clinical observations. In particular, age $<70$ years and the absence of premedication with an NSAID were statistically significant predictors of the need for rescue medication to manage chest pain.

The mechanism of the therapeutic effects of OK-432 for malignant effusion is thought to involve the induction of the release of various inflammatory cytokines, such as tumor necrosis factor- $\alpha$, interferon- $\gamma$, interleukin- 1 , and interleukin$8(5,6)$, which cause the fusion of the parietal and visceral pleurae; however, it is associated with an increased risk of adverse effects (chest pain and fever) from severe pleuritis. In this study, the rates of chest pain and fever due to pleurodesis with OK-432 were $43.6 \%$ and $40.4 \%$ respectively. This is consistent with previous reports $(1,4)$.

Chest pain was less common in elderly adults ( $\geq 70$ years) than in their younger adult counterparts ( $<70$ years). It is known that the immune response decreases with increasing age. Age-associated changes in the signal transduction and function of neutrophils and in the development and function of lymphocytes have been reported $(7,8)$. Given our finding that chest pain was less common in elderly adults, it may be that the inflammation triggered by the immune response to pleurodesis with OK-432 is milder in that age group. Fever was also less common in elderly adults; albeit, not significantly so.

The absence of premedication with an NSAID was a significant predictor of the need for rescue medication to manage chest pain. There is no consensus on the use of premedication for pleurodesis (9). Animal studies have shown that NSAIDs may impair the action of agents used for pleurodesis (10). Thus, there is a widespread belief that 
Table 3. Univariate Analysis of Factors Associated with Rescue Medication for Chest Pain after Pleurodesis.

\begin{tabular}{lcccc}
\hline & & OR & $95 \%$ CI & p value \\
\hline Age, years & $<70 / \geq 70$ & 2.60 & $1.11-6.10$ & 0.028 \\
Sex & Male/Female & 0.75 & $0.32-1.78$ & 0.514 \\
Body height, cm & $\geq 160 /<160$ & 1.43 & $0.62-3.31$ & 0.397 \\
Body weight, kg & $\geq 55 /<55$ & 0.50 & $0.22-1.16$ & 0.105 \\
Body surface area, m ${ }^{2}$ & $\geq 1.6 /<1.6$ & 0.56 & $0.24-1.32$ & 0.183 \\
Disease & Malignant pleural & 1.07 & $0.47-2.41$ & 0.877 \\
& effusion & & & \\
Albumin, g/dL & $\geq 3.2 /<3.2$ & 0.77 & $0.34-1.75$ & 0.533 \\
C-reactive protein, mg/dL & $\geq 3.0 /<3.0$ & 0.87 & $0.38-1.97$ & 0.736 \\
24-h drainage volume on the day & $\geq 150 /<150$ & 1.03 & $0.46-2.34$ & 0.936 \\
before pleurodesis, mL & & & & \\
Dose of OK-432 & $10 \mathrm{KE} / 5 \mathrm{KE}$ & 1.93 & $0.47-7.97$ & 0.365 \\
Administration of minocycline & Yes/No & 1.09 & $0.31-3.85$ & 0.896 \\
Administration of autologous blood & Yes/No & 2.33 & $0.70-7.74$ & 0.168 \\
Volume of solution & $100 \mathrm{~mL} / \leq 50 \mathrm{~mL}$ & 0.96 & $0.42-2.17$ & 0.919 \\
Administration of lidocaine 1\% & No/Yes & 0.99 & $0.44-2.24$ & 0.979 \\
NSAID & No/Yes & 4.22 & $1.64-10.85$ & 0.003 \\
Acetaminophen & No/Yes & 0.44 & $0.17-1.17$ & 0.099 \\
Opioid & No/Yes & 0.41 & $0.17-1.01$ & 0.053 \\
\hline OR: odds ratio, CI: confidence interval, KE: Klinische Einbeit, NSAID: nonsteroidal anti-inflammato- \\
ry drug & & & & \\
& & & &
\end{tabular}

Table 4. Multivariate Analysis of Factors Associated with Rescue Medication for Chest Pain after Pleurodesis.

\begin{tabular}{lcccc}
\hline & & OR & $95 \%$ CI & p value \\
\hline Age & $<70 / \geq 70$ & 2.97 & $1.10-8.00$ & 0.031 \\
Administration of autologous blood & Yes/No & 3.19 & $0.85-12.05$ & 0.086 \\
NSAID & No/Yes & 4.21 & $1.47-12.04$ & 0.007 \\
Acetaminophen & No/Yes & 0.72 & $0.16-3.18$ & 0.662 \\
Opioid & No/Yes & 0.68 & $0.18-2.51$ & 0.557 \\
\hline OR: odds ratio, CI: confidence interval, NSAID: nonsteroidal anti-inflammatory drug
\end{tabular}

NSAIDs should be avoided before the procedure. A multicenter randomized trial (TIME1) that compared the effects of opioids versus NSAIDs and larger versus smaller chest tube sizes on pain control in patients undergoing talc pleurodesis for malignant pleural effusion found that there was no significant difference in the pain scores of patients premedicated with NSAIDs or opiates and that the efficacy of pleurodesis at 3 months was not inferior in patients who were treated with NSAIDs (11). In terms of pleurodesis for spontaneous pneumothorax, it has been reported that the use of an NSAID obviates the need for narcotics without increasing the rate of recurrence (12).

The intrapleural administration of local analgesia just before the administration of the sclerosing agent has been suggested $(9,13)$; however, there is little evidence to support this recommendation. Furthermore, the present study shows that non-administration of lidocaine $(1 \%)$ did not increase the risk of chest pain. A prospective study is needed to determine whether the administration of lidocaine $(1 \%)$ has any benefit in patients undergoing pleurodesis. Pleurodesis with minocycline is reported to cause chest pain (14). However, the risk of chest pain was not increased in this study. This is thought to be due to the small number of patients who underwent pleurodesis with minocycline.

The present study is associated with several limitations, including its retrospective nature, single-center design, small study population, and a patient selection bias. In addition, this study did not review the relationship between success or failure and the complications of pleurodesis because the objective of this study was to analyze risk factors; the success of pleurodesis for malignant pleural effusion, and the incidence of complications of lung surgery and pneumothorax were not evaluated. It is necessary to investigate the association between the complications of pleurodesis and the outcomes. Furthermore, in Japan, OK-432 is the preferred sclerosing agent, whereas in Western countries talc pleurodesis has been the gold standard for the treatment of malignant pleural effusion for many years. Talc pleurodesis also causes chest pain and fever $(15,16)$. Further investigations are needed to identify the risk factors for complications caused 
Table 5. Univariate Analysis of Factors Associated with Fever after Pleurodesis.

\begin{tabular}{lcccc}
\hline & & OR & $95 \%$ CI & p value \\
\hline Age, years & $<70 / \geq 70$ & 2.07 & $0.88-4.84$ & 0.095 \\
Sex & Male/Female & 1.68 & $0.68-4.14$ & 0.260 \\
Body height, cm & $\geq 160 /<160$ & 1.67 & $0.71-3.91$ & 0.240 \\
Body weight, kg & $\geq 55 /<55$ & 0.90 & $0.39-2.07$ & 0.801 \\
Body surface area & $\geq 1.6 /<1.6$ & 0.84 & $0.36-1.95$ & 0.681 \\
Disease & Malignant pleural & 1.38 & $0.60-3.15$ & 0.447 \\
& effusion & & & \\
Albumin, g/dL & $\geq 3.2 /<3.2$ & 1.00 & $0.44-2.28$ & 0.999 \\
C-reactive protein, mg/dL & $\geq 53.0 /<3.0$ & 1.65 & $0.71-3.80$ & 0.242 \\
24-h drainage volume on the day & $\geq 150 /<150$ & 1.15 & $0.50-2.63$ & 0.740 \\
before pleurodesis, mL & & & & \\
Dose of OK-432 & $10 \mathrm{KE} / 5 \mathrm{KE}$ & 3.00 & $0.60-14.99$ & 0.181 \\
Administration of minocycline & Yes/No & 0.29 & $0.06-1.43$ & 0.128 \\
Administration of autologous blood & Yes/No & 0.61 & $0.18-2.16$ & 0.448 \\
Volume of solution & $100 \mathrm{~mL} /<50 \mathrm{~mL}$ & 2.22 & $0.95-5.20$ & 0.067 \\
Administration of lidocaine 1\% & No/Yes & 1.83 & $0.80-4.22$ & 0.154 \\
NSAID & No/Yes & 2.67 & $1.08-6.60$ & 0.034 \\
Acetaminophen & No/Yes & 0.60 & $0.23-1.57$ & 0.298 \\
Opioid & No/Yes & 0.94 & $0.39-2.30$ & 0.900 \\
\hline
\end{tabular}

OR: odds ratio, CI: confidence interval, KE: Klinische Einbeit, NSAID: nonsteroidal anti-inflammatory drug

Table 6. Multivariate Analysis of Factors Associated with Fever after Pleurodesis.

\begin{tabular}{lcccc}
\hline & & OR & $95 \%$ CI & p value \\
\hline Age & $<70 / \geq 70$ & 1.86 & $0.75-4.59$ & 0.181 \\
Dose of OK-432 & $10 \mathrm{KE} / 5 \mathrm{KE}$ & 1.12 & $0.16-7.81$ & 0.906 \\
Administration of minocycline & Yes/No & 0.37 & $0.06-2.48$ & 0.305 \\
Volume of solution & $100 \mathrm{~mL} / \leq 50 \mathrm{~mL}$ & 2.00 & $0.79-5.03$ & 0.141 \\
NSAID use & No/Yes & 2.43 & $0.95-6.22$ & 0.065 \\
\hline
\end{tabular}

OR: odds ratio, CI: confidence interval, KE: Klinische Einbeit, NSAID: nonsteroidal antiinflammatory drug

by pleurodesis with OK-432 and talc.

In conclusion, this study showed that age $<70$ years and the absence of premedication with an NSAID were risk factors for the need for rescue medication for the management chest pain. It might be better to consider premedication with an NSAID to prevent the chest pain caused by pleurodesis with OK-432. Furthermore, caution is advised in the management of chest pain in adults of $<70$ years of age. Prospective studies are needed to further investigate this issue.

The study was conducted in accordance with the Declaration of Helsinki and the protocol was approved by the Ethics Committee at Kyorin University Hospital (approval number: 776).

The authors state that they have no Conflict of Interest (COI).

\section{References}

1. Yoshida K, Sugiura T, Takifuji N, et al. Randomized phase II trial of three intrapleural therapy regimens for the management of ma- lignant pleural effusion in previously untreated non-small cell lung cancer: JCOG 9515. Lung Cancer 58: 362-368, 2007.

2. Kasahara K, Shibata K, Shintani H, et al. Randomized phase II trial of OK-432 in patients with malignant pleural effusion due to non-small cell lung cancer. Anticancer Res 26: 1495-1499, 2006.

3. How CH, Tsai TM, Kuo SW, et al. Chemical pleurodesis for prolonged postoperative air leak in primary spontaneous pneumothorax. J Formos Med Assoc 113: 284-290, 2014.

4. Ishida A, Miyazawa T, Miyazu Y, et al. Intrapleural cisplatin and OK432 therapy for malignant pleural effusion caused by non-small cell lung cancer. Respirology 11: 90-97, 2006.

5. Kitsuki H, Katano M, Ikubo A, et al. Induction of inflammatory cytokines in effusion cavity by OK-432 injection therapy for patients with malignant effusion: role of interferon-gamma in enhancement of surface expression of ICAM-1 on tumor cells in vivo. Clin Immunol Immunopathol 78: 283-290, 1996.

6. Tsuchiya I, Kasahara T, Yamashita K, et al. Induction of inflammatory cytokines in the pleural effusion of cancer patients after the administration of an immunomodulator, OK-432: role of IL-8 for neutrophil infiltration. Cytokine 5: 595-603, 1993.

7. Fulop T, Larbi A, Douziech N, et al. Signal transduction and functional changes in neutrophils with aging. Aging Cell 3: 217-226, 2004. 
8. Linton PJ, Dorshkind K. Age-related changes in lymphocyte development and function. Nat Immunol 5: 133-139, 2004.

9. Roberts ME, Neville E, Berrisford RG, Antunes G, Ali NJ; BTS Pleural Disease Guideline Group. Management of a malignant pleural effusion: British Thoracic Society Pleural Disease Guideline 2010. Thorax 65 (Suppl 2): ii32-ii40, 2010.

10. Hunt I, Teh E, Southon R, Treasure T. Using non-steroidal antiinflammatory drugs (NSAIDs) following pleurodesis. Interact Cardiovasc Thorac Surg 6: 102-104, 2007.

11. Rahman NM, Pepperell J, Rehal S, et al. Effect of opioids vs NSAIDs and larger vs smaller chest tube size on pain control and pleurodesis efficacy among patients with malignant pleural effusion: the TIME1 randomized clinical trial. JAMA 314: 2641-2653, 2015.

12. Ben-Nun A, Golan N, Faibishenko I, Simansky D, Soudack M. Nonsteroidal antiinflammatory medications: efficient and safe treatment following video-assisted pleurodesis for spontaneous pneumothorax. World J Surg 35: 2563-2567, 2011.
13. Kvale PA, Selecky PA, Prakash UB; American College of Chest Physicians. Palliative care in lung cancer: ACCP evidence-based clinical practice guidelines (2nd edition). Chest 132: 368S-403S, 2007.

14. $\mathrm{Ng}$ CK, Ko FW, Chan JW, et al. Minocycline and talc slurry pleurodesis for patients with secondary spontaneous pneumothorax. Int J Tuberc Lung Dis 14: 1342-1346, 2010.

15. Neragi-Miandoab S. Malignant pleural effusion, current and evolving approaches for its diagnosis and management. Lung Cancer 54: 1-9, 2006.

16. Inoue $T$, Ishida $A$, Nakamura $M$, Nishine $H$, Mineshita $M$, Miyazawa T. Talc pleurodesis for the management of malignant pleural effusions in Japan. Intern Med 52: 1173-1176, 2013.

The Internal Medicine is an Open Access article distributed under the Creative Commons Attribution-NonCommercial-NoDerivatives 4.0 International License. To view the details of this license, please visit (https://creativecommons.org/licenses/ by-nc-nd/4.0/).

(C) 2018 The Japanese Society of Internal Medicine Intern Med 57: 1697-1702, 2018 